Kotze, $\boldsymbol{H}$

University of Johannesburg

Spangenberg, ED

University of Johannesburg

E-mail: ericas@uj.ac.za

DOI: http://dx.doi. org/10.18820/2519593X/pie. v37i2. 2

ISSN 0258-2236

e-ISSN 2519-593X

Perspectives in Education

2019 37(2): 16-34

Date Published:

27 November 2019

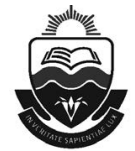

Published by the UFS

http://journals.ufs.ac.za/index.php/pie

(c) Creative Commons

With Attribution (CC-BY)

\section{Engineering students' actions in a mathematical modelling task: Mediating mathematical understanding in a computer algebra system}

\begin{abstract}
Many engineering subjects rely on the interpretation of symbolic, numeric and graphic representations. Engineering students have challenges pertaining to their mathematical understanding of their actions with a computer algebra system (CAS). We investigated how a mathematical modelling task could mediate varied levels of mathematical understanding. When engineering students are exposed to a CAS environment, they habitually engage in programming activities without considering the computerised outputs. The purpose of this paper was to ascertain South African engineering students' actions that can mediate broader levels of mathematical understanding in a CAS by utilising the PirieKieren model of growth in mathematical understanding. Thirteen participants agreed to engage collaboratively in a mathematical modelling task. The task was analysed by means of content analysis following a deductive research approach. The findings disclosed that engineering students interdepend on paper-and-pen, computerised and reflective actions in their growth of mathematical understanding. Engineering students can be assisted in mediated and folding-back actions in order to fluctuate back and forth on their way to a more sound mathematical understanding. Explicit planning and sequence of subtasks can support engineering students to merge new levels of mathematics understanding with past comprehensions. Thoroughly planned modelling tasks can mediate novel levels of mathematical understanding when engineering students learn with a CAS.
\end{abstract}

Keywords: Computer algebra system; differential equations; engineering students; mathematical modelling; Pirie-Kieren model; understanding.

\section{Introduction and background}

Engineering graduates of the 21st century face a technologically-driven world of work that is different from that of a few decades ago. Therefore, engineering students have to be exposed to a computer algebra system (CAS), such as Mathematica, which offers the user a symbolic, numeric and graphic interface (Dubinsky \& Tall, 1991). A CAS stimulates the use of other desirable mathematical 
tools for work-place engineers namely programming, mathematical modelling and visualisation (Aslaksen \& Santosa, 2013).

For students who are predominantly schooled in analytical procedures, such a technologyrich environment, a CAS implicates a shift from traditional paper-and-pen-based techniques. When engineering diploma students at the University of Johannesburg (UJ) are first exposed to a CAS, they find it challenging to understand computer generated graphs. The transition from a paper-and-pen learning background to a CAS environment can be difficult. Engineering students require "changing lenses" to bridge the "cognitive discontinuity" caused by different tools, a new computer language and multiple representations (Yerushalmy, 2005:37). Also, Berger (2010) argued that while the epistemic value of particular practices may be important in a paper-and-pen environment, it could be marginal in a CAS environment. A CAS responds to syntax-specific inputs, thereupon suppresses procedural processes and instantly displays outputs in the form of symbols, tables and graphs. Unlike in a paper-and-pen environment, the systematic step-by-step cognitive processes that would normally be followed, are outsourced to CAS. As such, students are confronted by a cognitive discontinuity (Yerushalmy, 2005). Those students who come from under-resourced teaching and learning backgrounds are often underprepared for the cognitive complexity imposed on them by a CAS.

Within a CAS task, students have to contextualise pre-knowledge from various mathematical domains into new situations. This re-contextualisation requires a past-to-present continuum that is emphatically part of mathematical problem solving. Hjalmarson, Wage and Buck (2008) highlighted that knowledge cannot remain detached in separate mathematical domains. Engineering students must be able to generate and interpret computer generated graphs by using various fields of mathematics in the final interpretation of graphs. Thus, future engineers require metacognitive skills to integrate their mathematical knowledge with their technological skills in order to logically interpret and analyse computer graphs.

Literature reveals substantial support for more research on the CAS domain of postschool mathematics. In a comprehensive review, Buteau, Marshall, Jarvis and Lavicza (2010) concluded that CAS in higher education is mainly integrated in mathematics major courses while service courses lag behind. Eighty-eight percent of the 204 articles analysed by Buteau et al. (2010) originated from the USA, 4\% from the UK and $8 \%$ from elsewhere in the world. Combined, Engineering and Science majors represented only $4 \%$ of the total number of courses incorporating CAS. Usiskin (2013) is of the opinion that the introduction of computer technology and graphing calculators in SA has not reached the benchmark of the rest of the world. This raises concerns about the under-represented body of research on using CAS within the vocational stream in SA. More specifically, further explorations can shed light on the particular challenges of engineering students when they interpret CAS-based outputs in both large- and small-scale studies (Berger, 2010). Stillman (2015) argued that CAS technologies supplement the difficulty of tasks and therefore recommended that the intellectual challenges enforced by real world problems be facilitated through thoroughly planned mathematical modelling tasks. Nevertheless, there is a scarcity of research on mathematical modelling as intervention for the intellectual difficulties imposed by a CAS environment. Therefore, the authors of this paper offer to address this gap by asking the question: Which actions can mediate broader levels of mathematical understanding in a CAS task? 


\section{Theoretical views}

Ang (2010:1) referred to mathematical modelling as a mathematical activity consisting of real world problems in order to interpret and solve the problems. For Niss, Blum and Galbraith (2007), the term mathematical modelling refers to an entire process. These authors argued that mathematics can be used to explain, investigate and understand the world outside mathematics. The extra-mathematical world is termed the real world and can involve another subject or discipline such as medicine or engineering. Objects, phenomena, facts or problems entrenched in the real world are translated into mathematical objects, facts or problems. In turn, these objects, facts and problems can be manipulated within the mathematical world where inferences can be made. The mathematical results can then be translated back into the real world where the original objects, phenomena, facts or problems can be validated. If the real world conclusions are not satisfactory, the modelling process can be repeated. Prominent characteristics of mathematical modelling focus on the mathematising of authentic situations (Yerushalmy, 1997) and collaborative activities that create an inherent social activity (English, 2003; Hamilton, Besterfield-Sacre, Olds \& Siewiorek, 2010; Zbiek \& Conner, 2006). According to Blum and Leiß (2007), the modelling cycle illustrates the modelling process which originates in the real world as an observed phenomenon in daily life. The real world problem then gets translated into a mathematical problem, a process called mathematising (Freudenthal, 1991). By acknowledging all relevant domains of mathematics, paper-and-pen graphs, sketches, diagrams or tables can be used to interconnect and contextualise the assumed relationships and equations to construct a mathematical model. The model is then solved mathematically; different representations such as graphs, tables and symbolic results can be constructed. The model needs to be validated to justify its appropriateness to the real world context. Should undesirable results emerge, it may be necessary to iterate the modelling cycle. Technology can be used in all phases of the modelling cycle to help understand the real life problem (Greefrath, Siller \& Weitendorf, 2011). Blum and Leiß (2007:225) proposed seven fundament skills to proceed from one phase of the modelling cycle to the next, namely 1) Understanding the task; 2) Simpifying/structuring; 3) Mathematising; 4) Working mathematically; 5) Interpretation; 6) Validation; and 7) Presenting. To move from one phase of the modeling cycle to the next, Galbraith and Stillman (2006: 144) identified seven generic modelling activities, namely A) Real world situation; B) Real world problem statement; C) Mathematical model; D) Mathematical solution; E) Real world meaning of solution; F) Evaluation; and G) Report. The modelling process is as follows: "A $\rightarrow$ B: understanding, structuring, simplifying, interpreting context; $\mathrm{B} \rightarrow \mathrm{C}$ : assuming, formulating, mathematising; $C \rightarrow D$ : working mathematically; $D \rightarrow E$ : interpreting mathematical output; $\mathrm{E} \rightarrow \mathrm{F}$ : comparing, critiquing, validating; $\mathrm{F} \rightarrow \mathrm{G}$ : communicating, justifying, report writing (if the model is considered to be satisfactory) OR $\mathrm{F} \rightarrow \mathrm{B}$ : revisiting the modelling process if the model is not satisfactory". A CAS can be utilised throughout the modelling cycle to advance mathematical understanding of the real world problem and, in turn, learning.

The Pirie-Kieren model is deemed appropriate to analyse growth in mathematical understanding in a CAS environment (Meagher, 2005). Pirie and Kieren (1994) viewed mathematical understanding as "a whole dynamic process and not as a single or multi-valued acquisition, nor as a linear combination of knowledge categories" (p. 165). According to Pirie and Kieren (1989), mathematical understanding is initiated by a primitive knowing that activates intuitive understanding. Specifically, Pirie and Kieren (1994) categorised eight levels of structured understanding namely, Primitive knowing (PK), Image making (IM), Image having (IH), Property 
noticing (PN), Formalising (F), Observing (O), Structuring (S) and Inventising (I). Inventising is the outer-most level where the structured understanding of a concept reaches a climax.

The level of PK is the start in the process of "coming to know" (Pirie \& Kieren, 1989: 8). This level is based on what the observer (i.e. a teacher or researcher) assumes students are doing. Such activities may involve the use of concepts or processes based on students' previous experiences. This level denotes to the entry-level understanding that will set the coming to know in motion.

The level of IM is directed by the images formed as a result of previous doing and knowing. These images may be in the form of mental images or concrete images that portray an understanding of a concept; images may also be quantities, comparisons or metaphors in an attempt to understand the nature of the problem or situation.

The level of $\mathrm{IH}$ is regarded as the first level of abstraction in the Pirie-Kieren model. By using and/or reviewing existing images formed on the IM level, understanding from doing is substituted an understanding emerging from seeing. Understanding can only develop if $\mathrm{IH}-$ images were self-produced.

On the level of PN, images can be scrutinised for features and prominent tendencies. In the instance where numerous images were established for a certain concept, characteristics and associations can be generated. A back-and-forth movement between different images builds understanding on all other inner levels in the model.

The level of $\mathrm{F}$ comprises the formal abstraction of accomplished images and associated understanding. Thus, features and properties noted in concept images can be formalised. $F$ can emerge by means of merging properties, definitions, equations, formulas or models.

The level of $O$ requires metacognition where thoughts are controlled and effects of thoughts are viewed. The cognisance of organised thoughts mediates reflection on actions in order to view, witness and communicate formulated understanding.

The level of $S$ anticipates the certainty, soundness and validation of the attained thoughts and understanding. All accomplished thoughts and understanding are at this point interconnected. Underlying ideas across all pertinent areas are organised in a lucid argument (Meel, 2003).

The furthest level of understanding is I. At this level, structured knowledge of a concept is exceeded when thoughts beyond the anticipated area of knowledge is being explored. The I level of understanding exceeds the restrictions of the initial concept being considered: understanding is creative, original and ground breaking when opportunities of 'what if' are contemplated (Meel, 2003).

The Pirie-Kieren model advocates that at each level, layers are nested. This entails that the outer layers hinge on understanding of the preceding, inner layers. Levels are not hierarchical, thus mathematical understanding at an outer level is not necessarily interpreted higher than understanding conveyed at an inner level. However, the fractal-like rings of the model symbolise the absorbing, yet encompassing nature of inner levels of understanding into an outer level. The transcendence of understanding is negotiated at different levels but must be compatible between levels. Understanding reached at one level is therefore not reducible to the previously visited level since at each level, understanding is "fundamentally new in some way, it has to be consistent with all previous levels of knowing" (Pirie \& Kieren, 1989:9). Understanding at a particular level can also sidestep some inner levels. For example, 
abstraction of thoughts may be displayed on the level of $F$ without necessarily demanding concrete images on the IM and/or IH inner levels. Pirie and Kieren (1994) labelled the backand-forth kinds of understanding as "folding back", explaining it as follows:

when faced with a problem or question at any level, which is not immediately solvable, one needs to fold back to an inner level in order to extend one's current, inadequate understanding. This returned-to, inner level activity, however, is not identical to the original inner level actions; it is now informed and shaped by outer level interests and understandings. (p. 173)

According to Blum and Borromeo Ferri (2009) the process of understanding through imaging is essential in the back-and-forth conversion between the real world and mathematical world (i.e. mathematising). A CAS environment shows students real life tasks that can stimulate their understanding when they have to visualise, generate, draw and evaluate mathematical models in real world terms. Thus, mathematical modelling provides an all-inclusive framework for understanding of mathematics and its relevance (Ang, 2010).

\section{Research design and methodology}

We adopted a real life world view where the gap between engineering mathematics curricula in SA where traditional approaches focus on close-ended theoretical problems founded in 20th century contexts on the one hand, and the demands from the engineering practice for real world problems situated in CAS contexts on the other hand, can be bridged by utilising mathematics modelling as a suitable learning approach (Stillman et al., 2013). Experiences faced in everyday living describe the nature of knowing but also affect students' means of doing mathematics and their understanding of the subject. The qualitative study is exploratory and formed part of a broader research project that investigated the influences of mathematical modelling in a CAS environment.

The study played out in an undergraduate course, Engineering Mathematics 3, which is a compulsory module for Electrical, Mechanical and Industrial Engineering students registered for a National Diploma in Engineering at UJ. The module is offered during each first semester to an Electrical Engineering cohort in their second academic year.

In the second year Engineering Mathematics 3 curriculum, differential equations (DEs) constitute the core topic. This curriculum is divided into a theory $(70 \%)$ and a practical component $(30 \%)$ where DEs are solved analytically and numerically. Analytical procedures are taught in the Engineering Mathematics 3 theory classes and follow strict theoretical procedures. Engineering Mathematics 3 students learn how to solve differential equations (DEs) numerically with Mathematica, a type of CAS. Once every week of the semester, students have to attend a practical session of 150 minutes in a computer laboratory. We analysed how engineering students connected their intuitive knowledge, mathematical understanding and technological skills when they had solved a differential equation (DE) that related to a real world problem. From a 2016 cohort of 139 students, thirteen students participated voluntary in this study. Two groups were formed by using prior assessment results; each group included low, average and top performers.

Over a period of two weeks, two mathematical modelling tasks were completed. This study reports on the second task which was designed in the form of a worksheet comprising nine subtasks. Worksheet documents in the form of handwritten text and electronic files were 
the primary sources of data to gain insights in students' actions, processes, objects, and ultimately their mathematical understanding. In this study, worksheet documents refer to hard or soft copies of a document that was used in a computer laboratory. On completion of the task, each group had to submit the worksheet document together with a task report to explain their thinking processes and difficulties encountered.

The modelling task consisted of a tollgate problem described the yearly retreat of pilgrims over the Easter weekend to the city of Moria, SA. The N1 National highway between the cities of Pretoria and Bela-Bela is known for traffic jamming, partly due to four tollgates as indicated in Figure 1. The differential equation (DE) that models the traffic movement on this part of the road was given as

$$
\frac{d N}{d x}=350 \cos \frac{2 \sqrt{x+0.15}}{\sqrt{x+0.15}}
$$

where $N$ point to the density of vehicles and $x$ the position on the road. The task was done just after the Easter weekend in 2016.

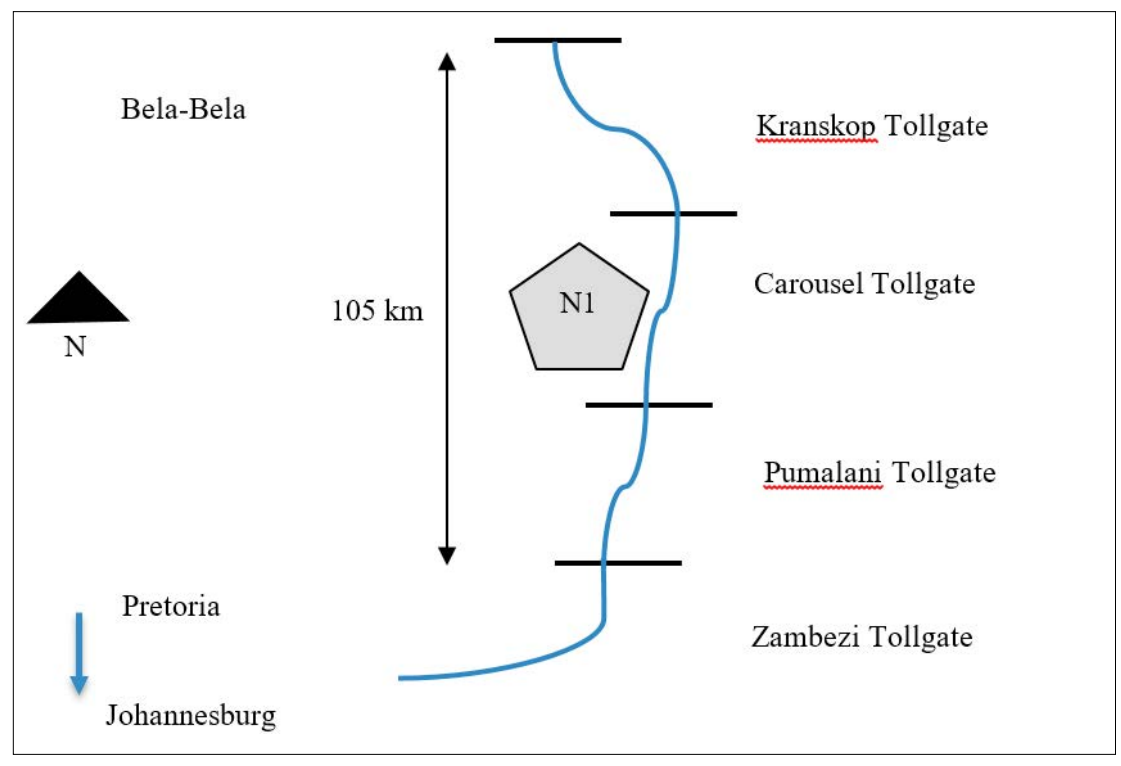

Figure 1: A map accompanying the tollgate task

Subtask one was intended to set students' coming to know in motion and prompted the Pirie and Kieren (1989) level of PK. In subtask two, students had to derive an initial condition (IC) from the given narrative and translate the IC symbolically. The initial condition of the DE had to be translated from the clue "assume there are 945 vehicles at the first tollgate". This implied a reversal since in the traditional classroom/laboratory lectures, the IC is always given and students merely have to substitute the IC into the DE.

In subtask three, students had to predict the solution without doing any formal mathematical analyses, which stimulated visual reasoning either by drawing a picture or by explaining in 
words. This subtask also elicited intuitive insight since students were compelled to interpret the narrative prior to extensive analysis and not only in retrospect (Nardi, 2014).

In subtask four, thereafter, students had to solve the DE analytically and generate a graph for the analytical solution They had to do it with paper-and-pen and had to programme the analytical solution. As subtask five, the analytical solution - a sinusoidal graph - had to be compared with the solution as predicted in subtask three. Such a comparison could facilitate links between the real world and the mathematical world. Supported by the analytical solution, subtask six required students to use their graphs and/or numerical values to read off the maximum number of vehicles that gather at any single tollgate. This subtask required a realworld interpretation of the sinusoidal function and its related maxima and minima.

Till now, all subtasks do not generally appear in the traditional teaching approach. Instead, numerical analyses with the Euler, Runge-Kutta order 2 and Runge-Kutta order 4 methods are preferred. In general, students learn to programme these numerical methods from first principles and do not simply rely on built-in Mathematica commands (such as DSolve). The numerical analyses of the DE were intentionally held back up to subtask seven in an attempt to provoke deeper understanding and mediate associations between the real world and the mathematical world. Programming with Mathematica (a type of CAS) assisted students to connect and correlate their symbolic, numeric and graphical representations. An interpretive question was presented in subtask eight: 'Is there a tollgate at the 50km mark? Give a reason for your answer.' For subtask nine, the distance between the Carousel and Kanskop tollgates (refer Figure 1) had to be calculated. On completion of the task, each group had to prepare a task report outlining their interpretations and/or challenges with particular subtasks.

The task prompted connections between the real world, mathematical world and technological world as showed in Figure 2. The tollgate task commences in the real world by means of a narrative that encouraged personal experiences in the real world; specially how traffic is distracted over peak travelling periods as suggested in the tollgate task. The tollgate incidence had to be converted into a mathematical problem by using mathematical knowledge, skill and understanding. The mathematical solution, a sinusoidal function, could then be investigated in the technological world by means of different representations namely graphical, numerical and symbolical. The different representations could be evaluated and correlated. Common sinusoidal characteristics such as minima and maxima could be understood mathematically but more notably, these meanings could assist to comprehend the congestion of cars at the four tollgates. 


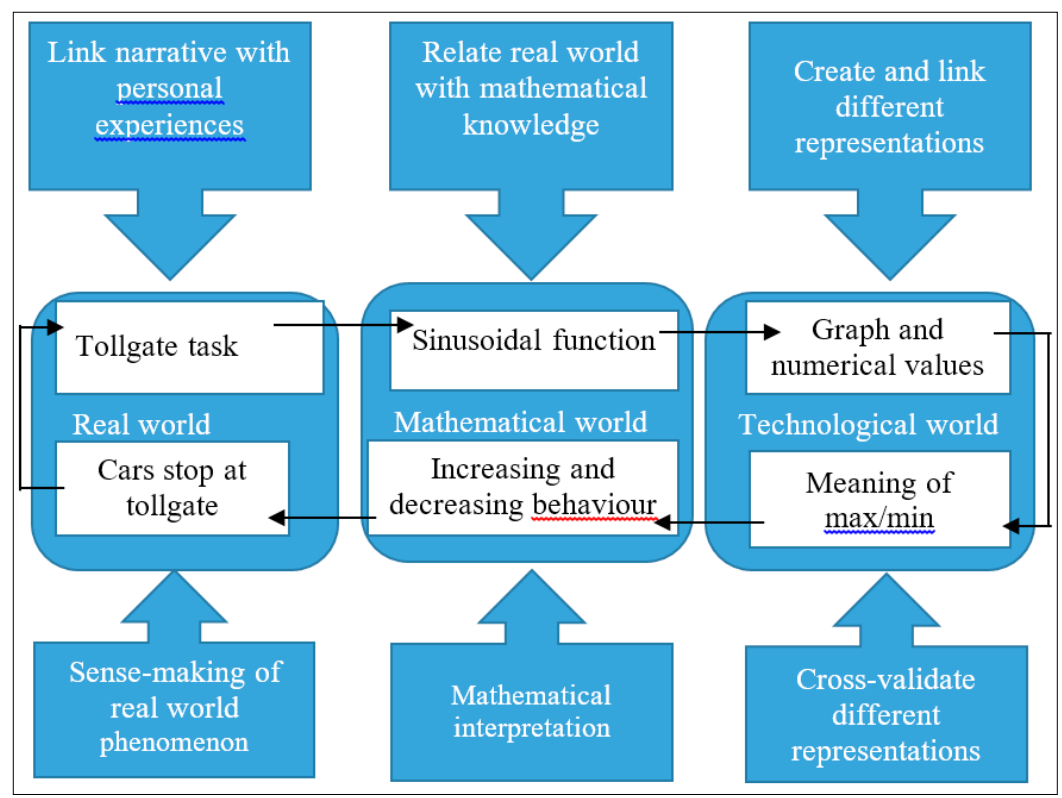

Figure 2: Linking three worlds while modelling with differential equations

\section{Data analysis}

Content analysis was used to analyse the task. The students' actions were utilised to code each group's task. In the case of experiential actions, two sub-themes differentiated between CAS (Mathematica) actions and paper-and-pen actions. In turn, these themes and subthemes were classified according to the eight Pirie-Kieren levels of understanding. In the subsequent section, the tollgate task of each group is analysed according to specific actions in each subtask.

\subsection{Group 1}

In subtask one, Group 1 sketched (action 1) a primitive hand-drawn diagram to visually interpret the lessening and broadening traffic flow along the four tollgates on the N1 highway (Figure 3). By using their daily experiences, these students disclosed their instinctive knowledge of how tollgates interrupt the flow of traffic. A lessening effect suggested the high density of vehicles as traffic move ahead to the tollgates. Figure 3 further suggests that as vehicles depart the tollgates, the traffic density speedily decreases and in that way generates a broadening result. The lessening and broadening occurrence was further labelled (action 2) with comments clarifying the traffic density as either "high" or "low". These comments, originated from students' experiences and impressions, served as hints that could possibly assist with later understanding (Kant, 1964). With the uncommon diagram illustrated in Figure 3, Group 1 portrayed the qualitative nature of the tollgate occurrence and thereby mathematised (action 3 ) the real world problem. These initial ideas, insights and considerations were ascertained on the Pirie-Kieren level of PK. Although only one of the six members in Group 1 resided in a province outside of Gauteng, this group offered a suitable interpretation of the tollgate occurrence which assisted them well in the following subtasks. 


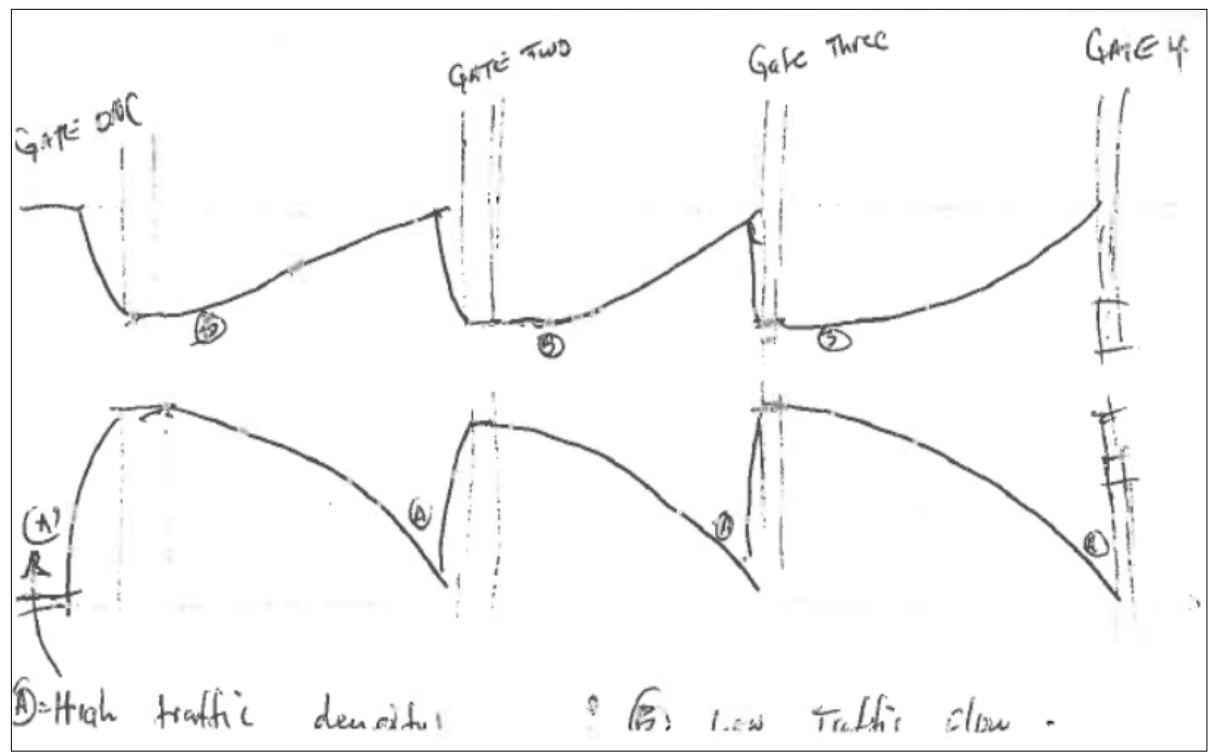

Figure 3: Group 1: PK of how four tollgates would affect traffic flow

In subtask two, Group 1 counted on the given narrative to interpret (action 4) the initial condition (IC) symbolically. It is likely that the high-low features noticed in the primitive diagram backed their conversion from the real world narrative and laid the foundation to formulate (action 5) the IC. Understanding turned to the PN level as the group attempted to predict (action 6) the solution in subtask three. These students sketched (action 7) an exponential solution as they predicted the traffic to "decrease with infinity" over time. It seems that Group 1 imagined (action 8) a more complete solution that could estimate the traffic density over the entire four-day period of the Easter weekend. In subtask four, students solved (action 9) the DE analytically using the separation of the variables method. They simplified (action 10) the DE by substituting the IC and obtained a sinusoidal solution with equation

$$
N=350 \sin (2 \sqrt{x+0.15})+700.2
$$

Equation 1

In subtask five, the analytical solution was compared (action 11) with their solution as predicted in subtask three but they grappled to reconcile (action 12) the sinusoidal solution with the exponential prediction. In order to validate (action 13) the solution, they generated (action 14) a Mathematica graph for the analytical solution and identified (action 15) the function: "it looks like a sine graph". Faced with conflicting solutions, these students were contested to critique (action 16) and in the end out rule the exponential solution. To this end, they combined (action 17) their primitive tollgate diagram with the exponential function to represent a longterm effect of the tollgates on the traffic flow. By superimposing (action 18) the exponential function onto the primitive tollgate diagram, they demonstrated their understanding of the lessening traffic density towards the end of the Easter weekend. This superimposed image would be compatible with students' knowledge of the steady state and transient state solutions of a DE. With this image, their understanding went further than the extent of the planned task and bordered on the Pirie-Kieren level of I. In subtask six, Group 1 predicted (action 19) the maximum number of vehicles that pile up at any single tollgate would be around 994 . 
According to their report, they (mis)calculated (action 20) this value by substituting $x=1$ in Eq.1. Since the maximum possible value of the first term in Eq. 1 is 350, the correct answer was $350+700.2=1050.2$. In subtask seven, students constructed (action 21 ) the RungeKutta order 4 (RK4) algorithm from first principles. They programmed (action 22) a code to get both a numerical table of values and a graph through which they could visualise and compare (action 23) the RK4 numerical values with the analytical values; this graph is presented in Figure 4.

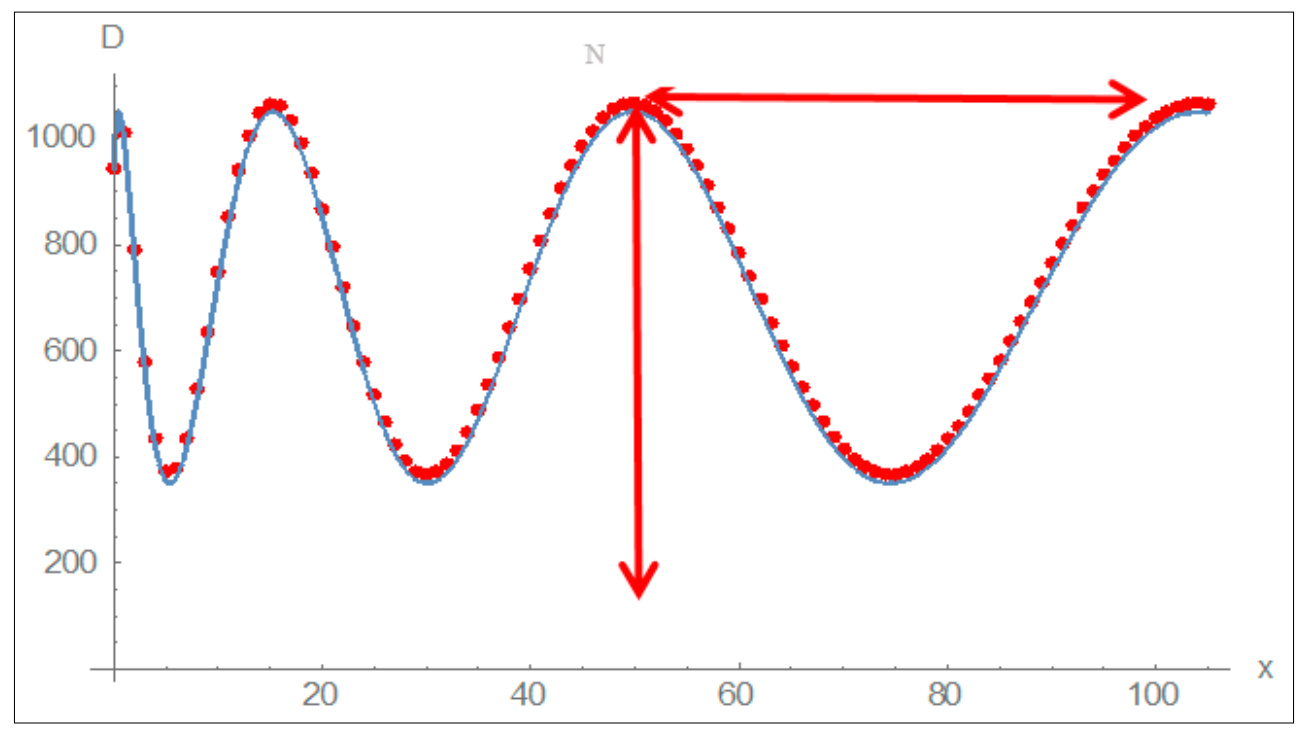

Figure 4: Group 1 identifying a tollgate at the $50 \mathrm{~km}$ mark and reading off the distance between the last two tollgates

In subtask eight, students interpreted (action 24) their graph (Figure 4) and explained (action 25) why there would be a tollgate at the $50 \mathrm{~km}$ mark. They could read off (action 26) a maximum value for $N$ where $x=50$ to confirm (action 27) the presence of a tollgate. Furthermore, they substantiated (action 28 ) this reality by cross-referring to the numerical table of RK4 values. In subtask nine, Group 1 read off (action 29) the distance between the Carousel and Kanskop tollgates utilising Figure 4; thereby justifying (action 30) their understanding that the maxima of the sinusoidal solution represent the position of the tollgates.

The 30 actions that were recorded for Group 1 are sequentially numbered in Table 1. 
Table 1: Thirty actions recorded for Group 1

\begin{tabular}{|c|c|c|c|c|}
\hline \multirow{3}{*}{$\begin{array}{l}\text { Pirie-Kieren level } \\
\text { (Pirie \& Kieren, } \\
\text { 1994) } \\
(n=8)\end{array}$} & \multicolumn{3}{|c|}{30 Sequential actions } & \multirow{3}{*}{$\begin{array}{l}\text { Generic modelling } \\
\text { activities (Galbraith \& } \\
\text { Stillman, 2006) } \\
(n=18)\end{array}$} \\
\hline & \multicolumn{2}{|c|}{ Experiential } & \multirow[b]{2}{*}{$\begin{array}{l}\text { Reflective } \\
\qquad(n=12)\end{array}$} & \\
\hline & $\begin{array}{l}\text { Computerised } \\
\qquad(n=3)\end{array}$ & $\begin{array}{l}\text { Paper-and-pen } \\
\qquad(n=15)\end{array}$ & & \\
\hline PK (3 actions) & & $\begin{array}{l}1 \text { Sketch } \\
2 \text { Label } \\
3 \text { Mathematise }\end{array}$ & & $\begin{array}{l}\text { Assuming: } \mathrm{B} \rightarrow \mathrm{C} \\
\text { Mathematising: } \mathrm{B} \rightarrow \mathrm{C}\end{array}$ \\
\hline IM (4 actions) & & $\begin{array}{l}7 \text { Sketch } \\
17 \text { Combine }\end{array}$ & $\begin{array}{l}8 \text { Imagine } \\
13 \text { Validate }\end{array}$ & $\begin{array}{l}\text { Interpreting context: } \mathrm{A} \\
\rightarrow \mathrm{B} \\
\text { Validating: } \mathrm{E} \rightarrow \mathrm{F}\end{array}$ \\
\hline IH (2 actions) & 14 Generate & & 23 Compare & $\begin{array}{l}\text { Working mathematically: } \\
C \rightarrow D \\
\text { Interpreting output: } \\
D \rightarrow E\end{array}$ \\
\hline PN (5 actions) & & $\begin{array}{l}4 \text { Interpret } \\
6 \text { Predict } \\
29 \text { Read off }\end{array}$ & $\begin{array}{l}12 \text { Reconcile } \\
15 \text { Identify }\end{array}$ & $\begin{array}{l}\text { Interpreting } \\
\text { output: } \mathrm{D} \rightarrow \mathrm{E} \\
\text { Validating: } \mathrm{E} \rightarrow \mathrm{F}\end{array}$ \\
\hline F (6 actions) & $\begin{array}{l}21 \text { Construct } \\
22 \\
\text { Programme }\end{array}$ & $\begin{array}{l}5 \text { Formulate } \\
9 \text { Solve } \\
10 \text { Simplify } \\
20 \text { Calculate }\end{array}$ & & $\begin{array}{l}\text { Formulating: } \mathrm{B} \rightarrow \mathrm{C} \\
\text { Working mathematically: } \\
\mathrm{C} \rightarrow \mathrm{D}\end{array}$ \\
\hline $\mathrm{O}$ (6 actions) & & $\begin{array}{l}19 \text { Predict } \\
26 \text { Read off }\end{array}$ & $\begin{array}{l}24 \text { Interpret } \\
25 \text { Explain } \\
27 \text { Confirm } \\
28 \text { Substantiate }\end{array}$ & $\begin{array}{l}\text { Communicating: } F \rightarrow G \\
\text { Report writing: } F \rightarrow G \\
\text { Interpreting output: } \\
D \rightarrow E\end{array}$ \\
\hline S (3 actions) & & & $\begin{array}{l}11 \text { Compare } \\
16 \text { Critique } \\
30 \text { Justify }\end{array}$ & $\begin{array}{l}\text { Comparing: } \mathrm{E} \rightarrow \mathrm{F} \\
\text { Critiquing: } \mathrm{E} \rightarrow \mathrm{F} \\
\text { Justifying: } \mathrm{E} \rightarrow \mathrm{F}\end{array}$ \\
\hline I (1 action) & & 18 Superimpose & & \\
\hline
\end{tabular}

In the first column of Table 1, actions are organised according to the Pirie and Kieren (1994) levels of mathematical understanding. A distinction is made between experiential and reflective actions in columns two, three and four. Experiential actions were traced in the worksheet and reflective actions were coded from the task report. Experiential actions were further sub-divided as either CAS (Mathematica) actions or paper-and-pen actions. In the last column, actions were aligned with Galbraith and Stillman's (2006) generic modelling activities. The conversions between specific modelling stages are indicated with arrows. For instance, mathematising is an activity associated with the movement between the real world problem statement (phase B) and mathematical model (phase $\mathrm{C}$ ) and thus annotated as B $\rightarrow \mathrm{C}$. 
Table 1 discloses that the majority of Group 1's actions were performed with paper-and-pen $(n=15)$, followed by reflective actions $(n=12)$ while the least number of actions performed were computerised $(n=3)$. The actions of Group 1 can be traced to all generic modelling activities as acknowledged by Galbraith and Stillman (2006). It is significant that within the first 20 actions, this group performed only one action (action 14) with the assistance of Mathematica. This result is in absolute contrast with the traditional learning approach where most activities are only performed with Mathematica. That means that in the traditional curriculum, most activities are executed symbolically through procedural processes; concentrating much on the F level of the Pirie-Kieren model. At the same time, Group 1 also reached all eight the PirieKieren levels of mathematical understanding. Even more unusual is that all eight Pirie-Kieren levels of mathematical understanding were appropriated within the first 19 actions. This finding can be interpreted that with the exception of action 14, all Pirie-Kieren levels of mathematical understanding were reached prior to computerised activities. Mathematical understanding was extensively unpacked on the PN level (5 actions), $\mathrm{F}$ level (6 actions) and O level (6 actions).

\subsection{Group 2}

The actions of Group 2 were to take a step back to the traditional teaching and learning approach. They began the task by programming (action 1) a Mathematica code to compute a RK4 solution of the given DE (subtask seven). In actual fact, they bypassed the first six subtasks. They generated (action 2) an incorrect RK4 graph as illustrated in Figure 5.

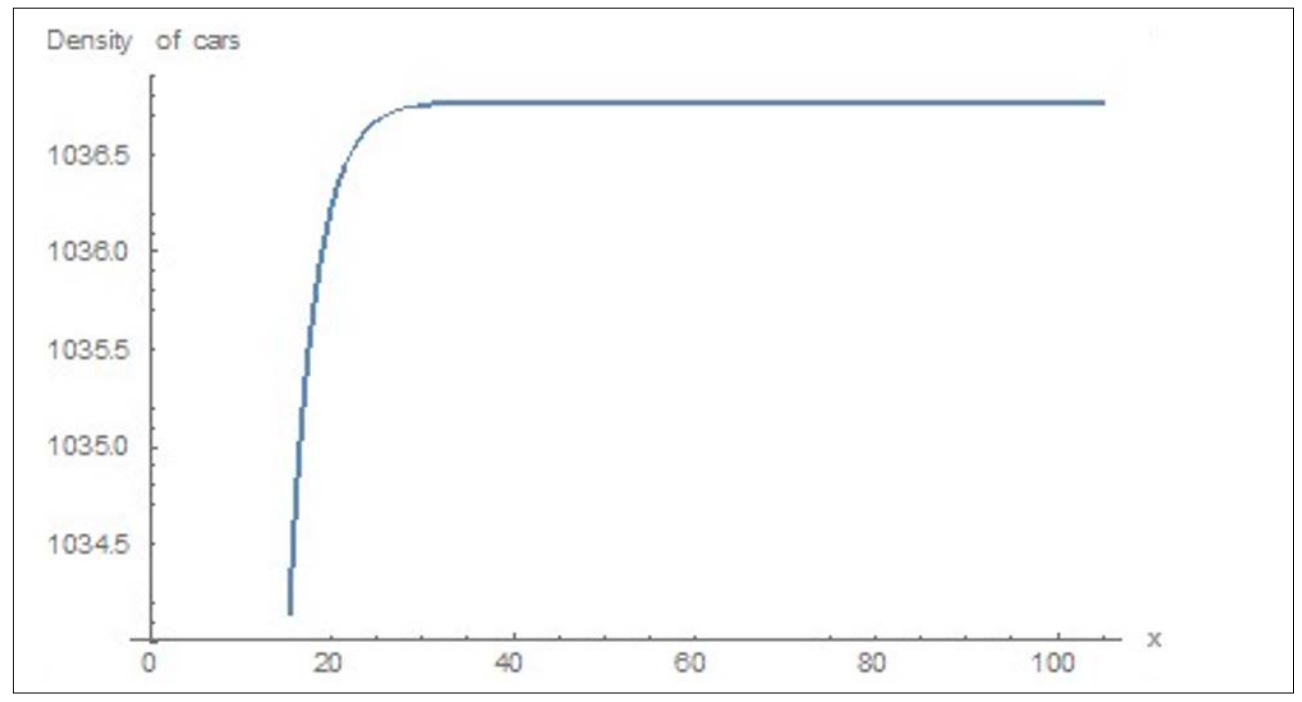

Figure 5: Incorrect Runge-Kutta order 4 (RK4) graph of Group 2

Their oversight was to swap the dependent and independent variable in their Mathematica code. The current teaching approach over-accentuates the use of $x$ as the independent and $y$ as the dependent variable where first order DE of the form $\frac{d y}{d x}$ are typically used. To a large extend, students are lacking ability in the use of atypical variable sets. Actually, Group 2 apprehended that something was wrong, yet fell short to debug their Mathematica code. Unexpectedly, they distributed the variables correctly on the axes when they copied Figure 5 in their task report. These students were nevertheless inattentive about this inconsistency. 
If this mistake was noted, they could have debugged their Mathematica code by switching the variables around. However, their task report disclosed how they attempted to interpret (action 3) their inaccurate RK4 graph as illustrated in Figure 6.

- We had an argumant on weatiner or not there is a
tollgate at the $80 \mathrm{ikm}$ marl, and fom the above $\frac{d N}{d X}$
graph, it is hard to tell since at the $50 \mathrm{~km}$ mark there is a consta
number of cars over the distance.

Figure 6: Example of a student's task report

These students were confused by their RK4 graph as they attempted to explain (action 4) whether there was a tollgate at the $50 \mathrm{~km}$ mark (subtask eight). They observed (action 5) a constant number of cars around the $50 \mathrm{~km}$ mark and beyond. This group became apprehensive of the (faulty) graph when they not succeed to identify any obvious tollgates: "we had an argument on weather (sic) or not there is a tollgate ... it is hard to tell". According to their task report, these students then tried subtask four - to solve the DE analytically - but to no avail. Uncared for, they relied on Mathematica's built-in commands to integrate (action 6) the righthand side of the DE, that is

$$
\int 350 \cos \frac{2 \sqrt{x+0.15}}{\sqrt{x+0.15}} d x .
$$

The appropriate Mathematica syntax would have necessitated them to include an initial condition for the 'Integrate' command, else the output would relate with the indefinite integral, lacking the constant of integration. Mathematica's output returned the analytical solution as

$$
N=350 \sin [2 \sqrt{x+0.15}] \text {. }
$$

Outsourcing the integration process to Mathematica was an unanticipated turn of events since the DE could have been solved by direct integration. Unwary of syntactic nuances, they generated (action 7) a Mathematica graph for the analytical solution as illustrated in Figure 7. Due to the neglected initial condition, the figure discloses (unrealistic) negative values to represent the density of cars. This observation went ignored, perhaps because their graph brings to mind the standard sine graph which fluctuates above and below the horizontal axis. More distressing, the maxima on the graph does not reflect the proposed initial condition of 945 vehicles at the first tollgate. 


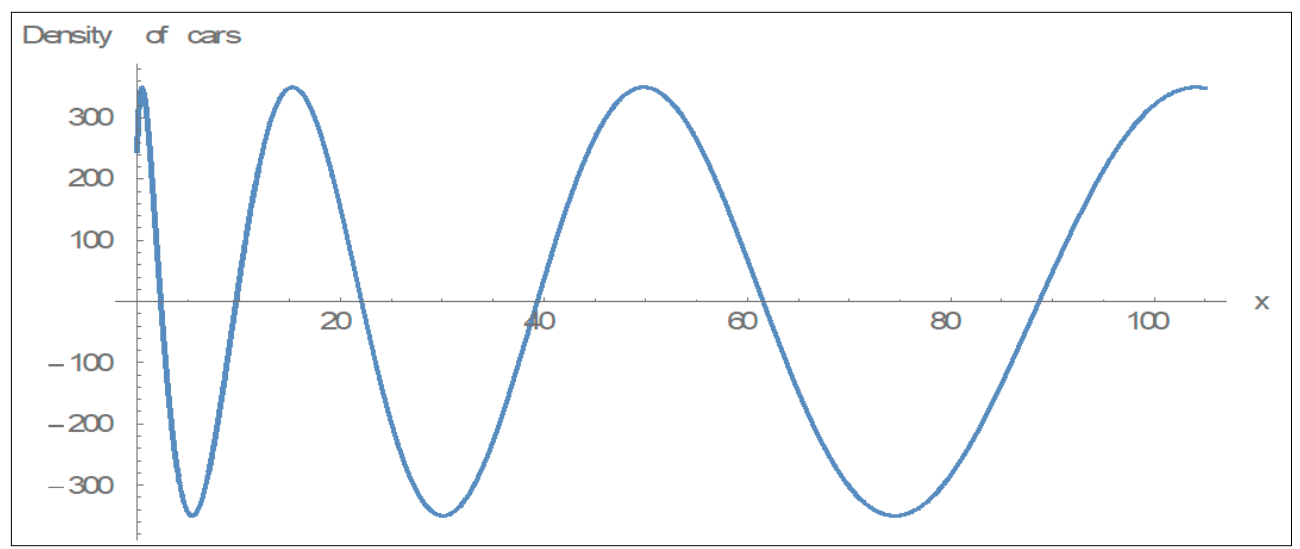

Figure 7: Analytical solution of Group 2 as they try to identify a tollgate at the $50 \mathrm{~km}$ mark

At this point, Group 2 had produced two separate but conflicting solution curves and tried to make sense (action 8) of these opposing figures. They compared (action 9) their RK4 solution (Figure 5) with their analytical solution (Figure 7). The latter appeared to be more compatible with their understanding of the tollgate occurrence. Lesh, Doerr, Carmona and Hjalmarson (2003: 223) stated that when students "become aware that two models are inconsistent, they begin to notice some of the differences" and seek the model that "appears to be fittest". Based on its features, Group 2 validated (action 10) the sinusoidal graph to be the best representation of the tollgate occurrence (revisiting subtask eight). In spite of outsourcing all symbolic processes to Mathematica, these students confirmed (action 11) in their task report "yes, there a tollgate at the $50 \mathrm{~km}$ mark. At the maximum amplitude of the graph there is a high count [of vehicles]".

Of the nine subtasks, Group 2 only finished three as they appeared to have been mirroring classroom practices. Only 11 actions were recorded for Group 2 and are encapsulated in Table 2. Yet, the understanding of Group 2 was structured on six of the eight Pirie-Kieren levels of mathematical understanding. Furthermore, all experiential processes were CAS-driven since these students did not execute any paper-and-pen actions. It is also worth mentioning that the majority of actions executed by Group 2 were reflective actions ( 7 actions). 
Table 2: Eleven actions recorded for Group 2

\begin{tabular}{|c|c|c|c|c|}
\hline \multirow{3}{*}{$\begin{array}{c}\text { Pirie-Kieren level } \\
\text { (Pirie \& Kieren, } \\
\text { 1994) }\end{array}$} & \multicolumn{3}{|c|}{11 Sequential actions } & \multirow[b]{3}{*}{$\begin{array}{l}\text { Generic modelling activities } \\
\text { (Galbraith \& Stillman, 2006) }\end{array}$} \\
\hline & \multicolumn{2}{|c|}{ Experiential } & \multirow{2}{*}{$\begin{array}{l}\text { Reflective } \\
\qquad(\mathrm{n}=7)\end{array}$} & \\
\hline & $\begin{array}{l}\text { Computerised } \\
\qquad(n=4)\end{array}$ & $\begin{array}{l}\text { Paper-and-pen } \\
\qquad(\mathrm{n}=0)\end{array}$ & & \\
\hline \multicolumn{5}{|l|}{$\mathrm{PK}$} \\
\hline IM (1 action) & 2 Generate & & & $\begin{array}{l}\text { Working mathematically: } \\
\qquad \mathrm{C} \rightarrow \mathrm{D}\end{array}$ \\
\hline IH (1 action) & 7 Generate & & & $\begin{array}{l}\text { Working mathematically: } \\
\qquad \mathrm{C} \rightarrow \mathrm{D}\end{array}$ \\
\hline PN (2 actions) & & & $\begin{array}{l}8 \text { Making } \\
\text { sense } \\
10 \text { Validate }\end{array}$ & $\begin{array}{c}\text { Interpreting output: } \mathrm{D} \rightarrow \mathrm{E} \\
\text { Validating: } \mathrm{E} \rightarrow \mathrm{F}\end{array}$ \\
\hline $\mathrm{F}$ (2 actions) & $\begin{array}{c}1 \text { Programme } \\
6 \text { Integrate }\end{array}$ & & & $\begin{array}{l}\text { Formulating: } C \rightarrow D \\
\text { Simplifying: } C \rightarrow D\end{array}$ \\
\hline O (3 actions) & & & $\begin{array}{l}3 \text { Interpret } \\
4 \text { Explain } \\
5 \text { Observe }\end{array}$ & $\begin{array}{c}\text { Communicating: } F \rightarrow G \\
\text { Report writing: } F \rightarrow G \\
\text { Interpreting output: } D \rightarrow E\end{array}$ \\
\hline S (2 actions) & & & $\begin{array}{l}9 \text { Compare } \\
11 \text { Confirm }\end{array}$ & $\begin{array}{l}\text { Comparing: } \mathrm{E} \rightarrow \mathrm{F} \\
\text { Confirming: } \mathrm{E} \rightarrow \mathrm{F}\end{array}$ \\
\hline 1 & & & & \\
\hline
\end{tabular}

It persists vague why Group 2 did not follow the sequence of subtasks in the worksheet but rather relied on known, well-rehearsed processes to finish the tollgate task. A possible reason may be that some students could have felt that the modelling task required them to think creatively but might not assist them during the test or examination. Another reason is offered by Berger (2012) who referred to different levels of engagement by different students, even though a CAS task may have been "designed with one pedagogic purpose and with appropriate mathematical and technical demands" (p. 266).

\section{Discussion}

The modelling task was different from the traditional computer laboratory approach where abstract DEs are solved using numerical methods and CAS. Instead, the task substantiated a $D E$ as a real life occurrence and provoked students' experiential mathematical understanding. While the underlying mathematics of the tollgate task was fairly straightforward and the Mathematica code-writing a familiar process, additional subtasks added a modelling flavour. For most of the task, students in Group 1 used CAS hardly to verify understanding with paperand-pen and reflective actions. This finding is similar to Dubinsky and Tall (1991) claiming that parallels should be drawn between programming actions and the way underlying mathematical processes are constructed. The subtasks outlined the means to navigate between mathematical concepts, CAS tools and real world contexts as these students appeared to draw on reality throughout the task. The origin of these students' mathematical understanding came in the form of a primitive but thought-provoking diagram (Figure 3). Accentuated by all eight Pirie-Kieren levels of mathematical understanding, actions were in 
sync with the real world contexts of the task. Understanding was verified by paper-and-pen, executed with technology and supported by plenty reflective actions. It was remarkable how 1) the tollgate phenomenon was visually imagined; 2) the primitive model offered understanding of the task and 3) the real world scenario were mathematised, prior to CAS analyses.

The findings firstly point toward an interdependence between paper-and-pen, computerised and reflective actions in the development of mathematical understanding. The way the modelling task was planned and arranged fostered a interaction between these three types of actions. Students in Group 1 not only merged their computerised actions with paper-andpen actions, but due to multiple paper-and-pen actions they could also deeply reflect on their CAS outputs. The interaction between computerised, paper-and-pen and reflective actions augmented these students' understanding of their computer-generated graphs. This finding is similar to Drijvers (2003) who observed that students' reflection by way of paper-and-pen actions can potentially enhance their interpretation of how computerised processes work and thereby deepen their understanding of computerised outputs. As a direct result of paper-andpen actions, the mathematical understanding of Group 1 was recurrently supported on the Pirie-Kieren levels of PK, PN and F (Table 1). Due to rich reflective actions, the understanding of Group 1 was further perceived on the Pirie-Kieren levels of $O$ and $S$. It is notable that Group 1 executed the task with minimal computerised actions (only 3 actions) but acquired considerable assistance from paper-and-pen and reflective actions. This finding is in contrast with students' normal actions during computer laboratory sessions when teaching and learning focus mostly on the Pirie-Kieren level of F. Group 1 could reach more Pirie-Kieren levels of mathematical understanding than Group 2 who largely relied on familiar computerised actions and reflective actions.

Group 2 failed to correlate their computer-generated results with paper-and-pen actions. To understand computerised processes requires some procedural knowledge of the internal mathematical processes that would normally have to be executed with paper-and-pen. Tall (1993) distinguished between external and analogue insight of computerised processes. A user is said to have external insight when knowledge of the internal workings of the computer is unclear. This may however not distract the user to cross-validate with paper-and-pen that the computer results are logical. For example, a student may not be aware of Mathematica's internal processes when a certain integral is computed, but by applying the relevant differentiation process the computer result can still be confirmed with paper-and-pen. A user with analogue insight is cognisant of the specific algorithm utilised by the computer and comprehends the mathematical basics of these internal processes. For example, even if a student is unfamiliar with Mathematica's integration syntax, a student with analogue insight will be cognisant that, in the lacking of an initial condition, the integration process will develop in a general solution that must include a constant of integration. Tall (1993) cautioned that a computerised algorithm may be misleading if the user is not mindful about the internal workings of the algorithm and recommends three ways in which to attend to internal computerised processes, namely enactive, procedural and symbolic. In the lacking of suitable paper-and-pen (procedural or symbolic) actions to confirm their Mathematica results, students in Group 2 failed to connect their CAS actions with basic theoretical principles. Students do not naturally associate their computerised misinterpretations with theoretical principles as in general through paper-andpen activities. This finding is similar to Drijvers (2003) who was of the view that students may be "unable to 'look through' the way the CAS arrived at its results, and cannot relate [the results] to their own experience[s] with paper-and-pencil techniques" (p. 90). Group 2 apparently 
found answers in their own real world experiences of toll roads which encouraged a variety of reflective actions. While it is possible that CAS actions were conventional, mathematical understanding was noticeably reinforced by considerable reflection on the logicality of CAS solutions. However, when paper-and-pen actions were allowed, even deep reflective actions could not effectuate sufficient mathematical understanding.

The findings secondly reveal that the way the tollgate task was parted into subtasks augmented development in mathematical understanding. Even when a specific subtask was totally wrong (Group 1, subtask three), mathematical understanding could be corrected, reflected upon and/or enhanced. Pirie and Kieren (1994: 173) labelled the back-and-forth characteristics of mathematical understanding as "folding back", explaining it as follows:

when faced with a problem or question at any level, which is not immediately solvable, one needs to fold back to an inner level in order to extend one's current, inadequate understanding. This returned-to, inner level activity, however, is not identical to the original inner level actions; it is now informed and shaped by outer level interests and understandings.

When mathematical understanding that was formed in later subtasks was despite everything disjointed, these mathematical understanding could be redirected to understanding framed in former subtasks. All together, the series of mediated and folding-back actions assisted students in Group 1 to fluctuate back and forth in the direction of a better logical mathematical understanding. In this case, the particular organisation and planning of subtasks assisted these students to merge new interpretations with prior experiences. This finding is in agreement with Vandebrouck (2018) who argues that subtasks can play a mediating role in tasks comprising technology.

\section{Conclusion}

The Pirie-Kieren (1994) model mediated the examination of non-linear mathematical understanding by assessing computerised, paper-and-pen and reflective actions of engineering diploma students while they executed a CAS task. We discovered that students' approaches and actions were prompted by the mathematical modelling characteristics of the task and the mediation of different actions through well-defined subtasks. The significance of mathematical modelling when students engage in a CAS ask for grounding status in engineering mathematics curricula. The prospective of well-structured CAS tasks are thus far unexploited.

\section{References}

Ang KC 2010. Teaching and learning mathematical modeling with technology (plenary lecture). Proceedings of the 15th Asian Technology Conference in Mathematics, December 17-21, 2010, Le Meridien, Kuala Lumpur, Malaysia, 19-29.

Aslaksen H \& Santosa F 2013. Technology issues. In: A Damlamian, JF Rodrigues \& R Sträßer (eds.), Educational interfaces between mathematics and industry - report on an ICMI-ICIAMstudy: 359-364. Cham: Springer. https://doi.org/10.1007/978-3-319-02270-3_36

Berger M 2010. Using CAS to solve a mathematics task: a deconstruction. Computers \& Education, 55(1): 320-332. https://doi.org/10.1016/j.compedu.2010.01.018

Berger M 2012. One computer-based mathematical task, different activities. Proceedings of the 36th conference of the International Group for the psychology of mathematics education. Taipei, Taiwan: PME, $259-266$. 
Blum W \& Borromeo Ferri R 2009. Mathematical modelling: can it be taught and learnt? Journal of Mathematical Modelling and Application, 1(1): 45-58.

Blum W \& Leiß D 2007. How do students and teachers deal with modelling problems? In: C Haines, P Galbraith, W Blum \& S Kahn (eds.), Mathematical modelling: education, engineering and economics - ICTMA 12: 222-231. Chichester, UK: Horwood Publishing. https://doi.org/10.1533/9780857099419.5.221

Buteau B, Marshall N, Jarvis D \& Lavicza Z 2010. Integrating computer algebra systems in post-secondary mathematics education: preliminary results of a literature review. International Journal for Technology in Mathematics Education, 16(2): 57-68.

Drijvers P 2003. Learning algebra in a computer algebra environment - design research on the understanding of the concept of parameter. Ph.D. Thesis, Netherlands: Utrecht University.

Dubinsky E \& Tall D 1991. Advanced mathematical thinking and the computer. In: D Tall (ed), Advanced mathematical thinking. Dordrecht: Kluwer Academic Publishers, 231-248. https:// doi.org/10.1007/0-306-47203-1_14

English L 2003. Mathematical modelling with young learners. In: SJ Lamon, WW Parker \& SK Houston, Mathematical modelling: a way of life - ICTMA 11: 3-17. Chichester: Horwood Publishing. https://doi.org/10.1533/9780857099549.1.1

Freudenthal H 1991. Revisiting mathematics education. Dordrecht: Kluwer Academic Publishers.

Galbraith P \& Stillman G 2006. A framework for identifying student blockages during transitions in the modelling process. ZDM Mathematics Education, 38(2): 143-162. https://doi. org/10.1007/BF02655886

Greefrath G, Siller H \& Weitendorf J 2011. Trends in teaching and learning of mathematical modelling. In: G Kaiser, W Blum, R Borromeo Ferri \& G. Stillman (eds), International perspectives on the teaching and learning of mathematical modelling. Dordrecht: Springer Netherlands, 315-329.

Hamilton E, Besterfield-Sacre M, Olds B \& Siewiorek N 2010. Model-eliciting activities in engineering: a focus on model building. Conference proceedings of American Society for Engineering Education, AC 2010-1501. Available from http://modelsandmodeling.net/ Publications_files/ASEE-10-Eric-FocusonModel Building.pdf

Hjalmarson MA, Wage KA \& Buck JR 2008. Translating information from graphs into graphs: systems and signals. Available from http://mathed.asu.edu/crume2008/Proceedings/ Hjalmarson\%20LONG.pdf

Kaiser G \& Schwarz B 2010. Authentic modelling problems in mathematics educationexamples and experiences. Journal für Mathematik-Didaktik, 31(1): 51-76. https://doi. org/10.1007/s13138-010-0001-3

Kant I 1964. Critique of pure reason, Revised Edition, Translated by JMD Meiklejohn. New York: Willey Book Co.

Kieran C \& Saldanha L 2008. Designing tasks for the co-development of conceptual and technical knowledge in CAS activity: an example from factoring. In: GW Blume \& MK Heid (eds), Research on technology in the teaching and learning of mathematics: cases and perspectives. Charlotte: Information Age, 2: 393-414.

Lesh RA, Doerr HM, Carmona G \& Hjalmarson M 2003. Beyond constructivism. Mathematical Thinking and Learning, 5(2-3): 211-233. https://doi.org/10.1080/10986065.2003.9680000 
Meagher M 2005. The processes of learning in a computer algebra system environment for college students learning calculus. Ph.D. dissertation. The Graduate School of Ohio State University, Ohio.

Nardi E 2014. Reflections on visualization in mathematics and mathematics education. In: MN Fried \& T Dreyfus (eds.), Mathematics \& mathematics education: searching for common ground: 3-24. Dordrecht: Springer. https://doi.org/10.1007/978-94-007-7473-5_1

Niss M, Blum W \& Galbraith P 2007. Introduction. In: W Blum, PL Galbraith., H -W Henn \& M Niss (eds.), Modelling and Applications in Mathematics Education. The 14th ICMI Study: 3-32. New-York: Springer. https://doi.org/10.1007/978-0-387-29822-1_1

Noss R, Healy L \& Hoyles C 1997. The construction of mathematical meanings: connecting the visual with the symbolic. Educational Studies in Mathematics, 33: 203-233. https://doi. org/10.1023/A:1002943821419

Meel DE 2003. Models and theories of mathematical understanding: comparing Pirie and Kieren's model of the growth of mathematical understanding and APOS theory. CBMS Issues in Mathematics Education, 12: 132-181. https://doi.org/10.1090/cbmath/012/06

Pirie S \& Kieren T 1989. A recursive theory of mathematical understanding. For the Learning of Mathematics, 9(3): 7-11.

Pirie S \& Kieren T 1994. Growth in mathematical understanding: how can we characterise it and how can we represent it? Educational Studies in Mathematics, 26(2-3): 165-190. https:// doi.org/10.1007/BF01273662

Schraw G 2013. Conceptual integration and measurement of epistemological and ontological beliefs in educational research, Review article, Hindawi Publishing Corporation ISRNEducation, Volume 2013, Article ID 327680. Available from http://dx.doi.org/10.1155/2013/327680

Stillman GA 2015. Applications and modelling research in secondary classrooms: what have we learnt? In: SJ Cho (ed), Selected Regular Lectures from the 12th International Congress on Mathematical Education. Cham: Springer, 791-805. https://doi.org/10.1007/978-3-319-17187-6_44

Tall D 1993. Interrelationships between mind and computer: processes, images, symbols. In: DL Ferguson (ed), Advanced technologies in the teaching of mathematics and science. New York: Springer-Verlag, 385-413. https://doi.org/10.1007/978-3-662-02938-1_14

Usiskin Z 2013. How SA can find safety in numbers. Mail \& Guardian, 27 July 2013. Available from http://mg.co.za/article/2013-07-27-how-sa-can-find-safety-in-numbers

Vandebrouck F 2018. Activity Theory in French Didactic Research. In: G Kaiser, H Forgasz, M Graven, A Kuzniak (eds), Invited Lectures from the 13th International Congress on Mathematical Education, ICME-13 Monographs. Cham: Springer International Publishing, 679-698. https://doi. org/10.1007/978-3-319-72170-5_38

Yerushalmy M 1997. Mathematizing verbal descriptions of situations: a language to support modeling. Cognition and Instruction, 15(2): 207-264. https://doi.org/10.1207/s1532690xci1502_3

Yerushalmy M 2005. Challenging known transitions: learning and teaching algebra with technology. For the Learning of Mathematics, 25(3): 37-42.

Zbiek R \& Conner A 2006. Beyond motivation: exploring mathematical modeling as a context for deepening students' understandings of curricular Mathematics. Educational Studies in Mathematics, 63(1): 89-112. http://dx.doi.org/10.1007/s10649-005-9002-4 